\title{
Programa Bolsa Família: a interface entre a atuação profissional e o direito humano a alimentação adequada
}

\author{
The "Bolsa Família" family grant scheme: the interface \\ between professional practice and the human right \\ to adequate food and nutrition
}

Camila Irigonhé Ramos ${ }^{1}$

Maria Rita Macedo Cuervo ${ }^{1}$

${ }^{1}$ Pontifícia Universidade Católica do Rio Grande do Sul. Avenida Ipiranga 6681, Partenon. 90619-900 Porto Alegre RS.

mila85@gmail.com

\begin{abstract}
The Human Right to Adequate Nutrition must be ensured through the public policies included in SAN, namely the Food and Nutritional Security campaign. Besides the income transfer geared to ensuring access to basic social rights, the "Bolsa Familia" Program (PBF) is included in this context. This study seeks to analyze the operational aspects of the PBF and also ascertain whether or not the health professionals see the program as a core element of the SAN public policy. With this in mind, semi-structured interviews were conducted with primary healthcare workers involved directly both with the PBF and with the families who receive this benefit. By the end of the study, it was possible to perceive the importance of training health professionals who work in this area, because when one dissociates the social reality in which the beneficiaries live from the program objectives, this can lead to the simple mechanization of these practices. In this respect, it should be stressed that health professionals need to understand the proposals of the program as political and social strategies which, in addition to providing immediate relief, strive to overcome the problems related to poverty and hunger.
\end{abstract}

Key words Food Security and Nutrition, Health professionals, Social Policy
Resumo O Direito Humano à Alimentação Adequada deve ser garantido através de políticas públicas de Segurança Alimentar e Nutricional (SAN). Nesse contexto está inserido o Programa Bolsa Família (PBF), que, além da transferência de renda, visa a garantia de acesso aos direitos sociais básicos. Este estudo objetiva analisar a operacionalização do PBF e, consequentemente, o entendimento dos profissionais de saúde a respeito do programa, enquanto eixo estruturante da política pública de SAN. Para isso, realizou-se entrevistas semiestruturadas com trabalhadores da atenção primária, envolvidos diretamente, tanto com o PBF, quanto com as famílias que recebem este beneficio. Ao final do estudo, foi possivel evidenciar a importância da formação dos profissionais que atuam nessa área, pois, ao desconectar a realidade social em que os beneficiários estão inseridos, dos objetivos do programa, colabora-se para a simples mecanização dessas práticas. Nesse sentido, aponta-se que os profissionais de saúde precisam entender as proposições do programa como estratégias político-sociais, as quais, para além do alivio imediato, visam a superação dos problemas relacionados à pobreza e à fome.

Palavras-chave Segurança alimentar e nutricional, Profissionais de saúde, Politica social 


\section{Introdução}

A alimentação, como processo sociocultural, vem sendo tema de diversos estudos. Por outro lado, a nutrição e as resultantes de uma má alimentação só entram em debate, no cenário brasileiro, a partir da década de 1930, com as pesquisas realizadas pelo médico Josué de Castro, responsável por denunciar o flagelo da fome para o Brasil e o mundo. Segundo esse autor, "a fome coletiva é um fenômeno social bem mais generalizado. É um fenômeno geograficamente universal, não havendo nenhum continente que escape à sua ação nefasta" ${ }^{1}$. Com os estudos do pesquisador, dá-se inicio à modificação do conceito de fome, que começa a ser encarada como um problema social.

Dessa forma, se iniciam os debates sobre a fome e o direito à alimentação. Em nível internacional, apenas em 1948 passa a ser vista como um direito. Tal processo está intimamente ligado à Declaração Universal dos Direitos Humanos (ONU, 1948), a qual, em seu artigo XXV ressalta: "toda pessoa tem direito a um padrão de vida capaz de assegurar a si e a sua família saúde e bem estar, inclusive alimentação, vestuário, habitação [...]"2.

No Brasil, as discussões sobre a alimentação como um direito constitucional entram em pauta, de fato, no ano de 2004, após a II Conferencia Nacional de Segurança Alimentar e Nutricional. Nesse período, o Conselho de Segurança Alimentar e Nutricional (CONSEA) em parceria com o Ministério do Desenvolvimento Social e Combate a Fome (MDS), propõe a Lei Orgânica de Segurança Alimentar e Nutricional (LOSAN), que tem como objetivos: garantir o direito à alimentação adequada para todos os brasileiros e brasileiras como direito humano; definir o conceito de segurança alimentar e implantar o Sistema Nacional de Segurança Alimentar e Nutricional ${ }^{3}$.

A alimentação como um direito constitucional é uma conquista recente. Passados mais de cinquenta anos da Declaração Universal dos Direitos Humanos, a sociedade civil brasileira consegue inserir na Constituição, por meio da Emenda Constitucional no 64 (2010), uma determinação legal que assegura ser este um direito de toda a população ${ }^{4}$. Nesse sentido, o Direito Humano a Alimentação Adequada (DHAA) deve ser garantido através de políticas públicas de Segurança Alimentar e Nutricional (SAN). Lembrando que a SAN é:

a realização do direito de todos ao acesso regular e permanente a alimentos de qualidade, em quantidade suficiente, sem comprometer o acesso a outras necessidades essenciais, tendo como base práticas alimentares promotoras da saúde, que respeitem a diversidade cultural e que sejam social, econômica e ambientalmente sustentáveis.

A principal estratégia adotada para combater a fome e a miséria no Brasil, o Programa Fome Zero, entrou em curso no ano de 2003. Esse conjunto de princípios visa garantir o DHAA e se insere na promoção da $\mathrm{SAN}^{6}$.

O Fome Zero divide-se em quatro eixos, os quais, articulados, buscam atingir os objetivos do programa. São eles: acesso à alimentação; geração de renda; fortalecimento da agricultura familiar e articulação, mobilização e controle social. No eixo que trata do acesso à alimentação, o DHAA, é assegurado por meio de programas de alimentação e nutrição, de incentivos fiscais, de redução de tributos e de programas de transferência condicionada de renda, como o Programa Bolsa Família (PBF). Embora a transferência condicionada de renda seja apenas um dos pontos de articulação do PBF, ressalta-se que, as famílias beneficiárias e o poder público, assumem o compromisso com o cumprimento das condicionalidades, visando ampliar o acesso dos beneficiários aos seus direitos sociais básicos ${ }^{7}$.

No PBF, o acompanhamento das condicionalidades se dá em três setores: educação, assistência social e saúde. Em relação a esta última, destaca-se que há papeis e ações definidas para as secretarias municipais e estaduais do setor. A legislação do programa ratifica a responsabilidade do município quanto "a oferta de serviços e de gestão do acompanhamento do cumprimento das obrigações das famílias beneficiadas"7-8. Em nível local, as famílias beneficiárias devem ser acompanhadas e assessoradas em Unidades Básicas de Saúde (UBS) contempladas, ou não, com a Estratégia de Saúde da Família7.

Para atingir os objetivos almejados pelo PBF é importante que ele esteja articulado com outros tipos de intervenção política e, além disso, seja executado intersetorialmente. Tais práticas visam a capacitação das famílias na utilização do dinheiro recebido, acessando, de maneira segura e saudável, os alimentos, e, principalmente, levando em consideração que, esse acesso seguro, deve ser sanitário, nutricional, cultural e sustentável 9 .

Diante do exposto, o presente estudo objetiva analisar a operacionalização do PBF e, consequentemente, o entendimento dos profissionais de saúde a respeito do programa, enquanto eixo estruturante da política pública de Segurança Alimentar e Nutricional. Utiliza-se a palavra operacionalização com intuito de evidenciar o funcio- 
namento técnico do PBF, ou seja, como, na prática, o programa é desenvolvido pelos profissionais da atenção primária.

\section{Métodos}

Para a realização desta pesquisa optou-se pela utilização da abordagem qualitativa. Tal metodologia trabalha com representações, valores, opiniões, processos e fenômenos que não são mensuráveis por variáveis quantitativas ${ }^{10-12}$. Participaram do estudo os coordenadores das unidades de saúde e os profissionais responsáveis por desenvolver o acompanhamento das famílias em relação à condicionalidade saúde.

$\mathrm{Na}$ escolha dos participantes, levou-se em consideração que, para atingir os desígnios do programa, os envolvidos com o Bolsa Família precisariam ter entendimento dos objetivos propostos, sobretudo em relação à SAN e ao DHAA. Só assim esses profissionais podem orientar os beneficiários de modo satisfatório, diminuindo o risco de o programa ser desenvolvido e implementado em caráter meramente assistencial e compensatório.

O tamanho da amostra foi definido pelo critério de saturação. Dessa forma, o fechamento amostral sobreveio no momento em que os dados obtidos, por intermédio de novos componentes, começaram a apresentar certa redundância, ou seja, quando as categorias em estudo apresentarem-se saturadas ${ }^{13}$.

Realizou-se a pesquisa em Unidades Básicas de Saúde e Unidades de Saúde da Família, todas de gestão municipal, situadas em uma das gerências distrital do município de Porto Alegre/ RS. Para a escolha da gerência levou-se em consideração o fato de que este distrito de saúde é uma das regiões mais vulneráveis do município. Os índices de desemprego e escolaridade são os mais baixos da capital ${ }^{14}$. Nesse sentido, compreende-se que, nestas áreas geográficas, as famílias necessitam de maior auxilio do governo para acessarem suas necessidades sociais básicas e, de certa forma, há um grande número de famílias beneficiárias do PBF.

$\mathrm{Na}$ coleta de dados foram utilizadas técnicas de entrevista semiestruturada e observação. A entrevista foi guiada por pontos de interesses, sendo estes aplicados sistematicamente no direcionamento da conversa. Foi permitido ao entrevistado se expressar livremente, pois não se empre- gou muitas perguntas diretas. Com o intuito de não perder o foco do estudo, a condução da entrevista esteve amparada em um roteiro, previamente elaborado. Este procedimento contribuiu, ainda, de maneira a auxiliar na finalidade da pesquisa e no estímulo a respostas completas ${ }^{15}$.

As entrevistas foram gravadas com a concordância dos participantes e, posteriormente, transcritas, analisadas e destruídas. A contribuição de todos os entrevistados se deu voluntariamente. Para manter o sigilo e preservá-los, colocou-se, ao final das falas, o número de identificação da entrevista. Respeitando-se, assim, a Resolução No 196/96 com pesquisas envolvendo seres humanos, desenvolvida pelo Ministério da Saú$\mathrm{de}^{16}$. Salienta-se, ainda, que os participantes receberam um termo de consentimento livre e esclarecido. Após a leitura e a concordância com o descrito no mesmo, cada um assinou o documento e consentiu fazer parte do estudo.

Realizou-se a análise dos dados a partir da categorização dos temas, conforme Bardin ${ }^{17}$. Por meio da relação entre as categorias, as quais foram agrupadas através do critério semântico, torna-se possível estabelecer interpretações e explicações propositivas. Quanto aos aspectos éticos, destaca-se que, o presente estudo, foi aprovado pelo Comitê de Ética em Pesquisa da Pontifícia Universidade Católica do Rio Grande do Sul e pelo Comitê de Ética em Pesquisa da Secretaria Municipal de Saúde de Porto Alegre.

\section{Resultados e discussão}

\section{A representação dos entrevistados}

Das onze unidades de saúde que fizeram parte do estudo, três são Unidades Básicas de Saúde e oito, Unidades de Saúde da Família, totalizando 23 entrevistados. Dentre eles, 11 coordenadores e 12 profissionais responsáveis pelo acompanhamento das famílias. A amostra dos coordenadores foi composta por nove enfermeiros, uma médica, e uma dentista. Entre os profissionais que realizam o acompanhamento da condicionalidade saúde sete são agentes comunitários de saúde, dois são nutricionistas e três são técnicos de enfermagem. Em relação ao tempo de serviço, a maioria dos profissionais trabalha há mais de dez anos na atenção primária. Para melhor compreender os resultados os dados serão apresentados em categorias e subcategorias. 
Direito Humano a Alimentação Adequada e Segurança Alimentar e Nutricional: da teoria à prática

O conceito de Segurança Alimentar e Nutricional (SAN) encontra-se em constante construção, modificando-se, significativamente, ao longo das últimas décadas. Revisitando o inicio do século XX, é possível descrever as diversas etapas de sua elaboração. Trata-se, pois, de uma questão histórica. Com o período do entre guerras e a recessão econômica de 1930, a problemática da fome, amplificada a partir desses acontecimentos, passa a determinar o conceito de Segurança Alimentar. Nessa época, as políticas alimentares eram voltadas para o problema dos preços altos e da falta de alimentos ${ }^{3}$.

A mesma imagem sobre a Segurança Alimentar é utilizada no Brasil até meados da década de 60. Nesse período, uma estrutura de estocagem e distribuição é criada nacionalmente. Já no decênio seguinte, ocorre a ampliação da interferência pública e o Estado começa a atuar no incentivo à produção agrícola. Neste exato momento histórico está ocorrendo a Revolução Verde, com a adoção do pacote tecnológico e a utilização intensa de agrotóxicos, adubos químicos e outros fertilizantes. Tal fenômeno ocasionou o aumento das despesas com o cultivo e o endividamento dos pequenos agricultores, o crescimento da dependência dos países, do mercado e da lucratividade das grandes empresas de insumos agrícolas ${ }^{3,18}$.

Com o advento da Revolução Verde, o Brasil e o mundo começam a acreditar que o problema da fome e da desnutrição estaria resolvido. No entanto, a ampliação da produção agrícola não ameniza o número de famintos, os quais aumentam gradativamente. Isso porque o acesso aos alimentos por parte da sociedade em geral não depende somente da produção, mas sofre influência, também, das formas sociais que interferem na produção e oferta desses produtos ${ }^{3,19}$.

Nos anos 90, o conceito de Segurança Alimentar é ampliado e renovado. Com isso, o termo, agora expresso por meio da Segurança Alimentar e Nutricional, enfatiza o acesso aos alimentos em quantidade e qualidade, devendo estar adequado social, econômica e culturalmente. Dois momentos distintos marcam esse período. Na primeira metade da década, em decorrência da adoção de políticas neoliberais, são realizadas manifestações em torno do tema de combate à fome e a miséria, o que resulta na formação de uma instituição de caráter nacional, o Conselho Nacional de Segurança Alimentar (CONSEA). Já na segunda metade da década de 90 , ocorre o desmonte das estruturas anteriores e a gradativa adesão do governo federal, encabeçado pelo expresidente Fernando Henrique Cardoso (FHC), às políticas de articulação com as comunidades $\mathrm{e}$ o fornecimento de programas de renda mínima, do tipo bolsa-escola ${ }^{19}$.

As denúncias do Mapa da Fome, de 1993, e, concomitantemente, a exclusão das questões referentes à fome e à miséria da agenda política brasileira, resultaram na mobilização da sociedade civil em torno das discussões sobre a SAN e o Direito à alimentação. Esse processo culminou na criação da Ação da Cidadania Contra a Miséria e Pela Vida, fortemente influenciada pelo Movimento pela Ética na Política. Liderada pelo sociólogo Herbert de Sousa, o Betinho, a Ação pela Cidadania buscava sensibilizar a população para a necessidade de mudança na estrutura política e econômica vigente no país. O objetivo era, ao mesmo tempo, solucionar o problema da fome de forma imediata e promover a conscientização da sociedade para a necessidade de mudança no quadro de carência alimentar que estava instaurado. Toda essa mobilização culminou na I Conferência nacional de SAN, realizada ainda no ano de 1994, um ano antes de FHC assumir a presidência da República ${ }^{20-21}$.

Durante o Governo FHC, começa a funcionar o plano de estabilização da moeda nacional, popularmente conhecido como Plano Real. Paralelo ao fortalecimento dessa estratégia financeira ocorre o rompimento das relações políticas com os setores da sociedade brasileira que defendiam uma política de Segurança Alimentar e Nutricional. Assim, o tema da fome é colocado em hibernação ${ }^{18}$. Nesse período, o CONSEA é extinto e o Governo cria o programa Comunidade Solidária, responsável por diluir os objetivos da SAN. Apesar disso, em 1998, cria-se o Fórum Brasileiro de Segurança Alimentar e Nutricional, iniciativa das organizações sociais, que vem contribuindo, desde então, para as formulações sobre SAN no Brasil ${ }^{3}$.

Em seu discurso de posse, no dia $1^{\circ}$ de Janeiro, de 2003, Luiz Inácio Lula da Silva retoma a polêmica da fome e traça metas para combatêla. Lula institui o Programa Fome Zero (PFZ) como estratégia para o combate à fome e à miséria e, além disso, nomeia os novos membros para o CONSEA ${ }^{3}$.

\section{DHAA e saúde: o que os profissionais conhecem e entendem sobre o conceito e como se relacionam com ele}

A maioria dos entrevistados relatou nunca ter ouvido falar do DHAA, mesmo assim o reco- 
nhecem como um direito. Entre aqueles que tiveram algum contato com o tema, pode-se perceber que essa relação é incipiente. De acordo com o que se explicita nas falas abaixo:

A gente escuta falar bastante das questões dos direitos humanos, mas eu confesso que, direitos humanos, quanto à alimentação saudável, eu nunca ouvi falar (E17).

Já, já ouvi falar de todos os direitos (E13).

Especificamente não ouvi falar. Mas eu acho que todo mundo tem direito a uma alimentação básica (E16).

Quanto aos que demonstraram ter alguma informação sobre o assunto, percebe-se, em suas falas, uma forte descrença tanto na garantia quanto no cumprimento e exercício desse direito. Descrédito, esse, expresso, respectivamente, nas autoridades governamentais e na prática das famílias beneficiárias. Desse modo, evidencia-se a desconfiança dos profissionais sobre as relações que permeiam o DHAA. Conforme se constata a seguir:

Já ouvi falar. Acho que não existe. Pode ter até no papel, mas não existe. Aqui muitas pessoas passam fome de verdade, então, se o direito existe, aqui, ele não tá entrando (E6).

Eu acho que o poder público e, esses direitos, todos eles, demoram (E7).

A pessoa pode ter o direito e não usufruir do direito (E21).

A partir dessas constatações é possível afirmar que, os profissionais da saúde, têm pouca aproximação com a problemática dos direitos sociais, seja no âmbito teórico, seja no prático. Deve-se atentar para esse fato, uma vez que, tais trabalhadores, precisam ser "capazes de enfrentar os problemas resultantes da pobreza e da desigualdade social, tão presentes no cotidiano brasileiro" ${ }^{22}$. Na contramão desta evidência, atenta-se para uma série de acontecimentos, pois as discussões sobre as desigualdades sociais e a saúde foram amplamente debatidas no $11^{\circ}$ Congresso Mundial de Saúde Pública e $8^{\circ}$ Congresso Brasileiro de Saúde Coletiva, ambos realizados em agosto de 2006, no Rio de Janeiro, cujo tema em destaque era, justamente, Saúde Coletiva no mundo globalizado: rompendo barreiras sociais, econômicas e políticas. No mesmo ano, antecedendo estes eventos, em março de 2006, foi criado a Comissão Nacional sobre Determinantes Sociais em Saúde (CNDSS). Além disso, o Brasil foi um dos primeiros países a receber apoio e incentivo da Organização Mundial da Saúde (OMS) para participar desta Comissão ${ }^{22}$.
Considerando todos esses fatos, torna-se ainda mais preocupante que o DHAA seja um tema pouco explorado e discutido nos serviços de saúde. Fenômeno, este, que pode estar atrelado ao modelo de atenção à saúde vigente no país, o qual "traz a atenção à saúde centrada na assistência curativa, hospitalar e superespecializada, na vertente de interesses econômicos e corporativos" ${ }^{23}$. Aliado a isso, deve-se considerar a divisão do trabalho, responsável pelo distanciamento entre uma elite intelectual, formada por profissionais de saúde que participam recorrentemente desses congressos e a base dos trabalhadores da saúde, que operam as políticas sociais, mas, até mesmo em função de seu trabalho, acabam isolados dessas discussões.

Levando em consideração que o DHAA deve ser garantido por meio de políticas públicas de SAN, busca-se, com o presente artigo, investigar qual a compreensão dos entrevistados a respeito do tema. Nota-se, inclusive, que, a maioria dos sujeitos da pesquisa, relaciona o conceito aos cuidados com as crianças, com a qualidade e a quantidade da alimentação e com a obrigatoriedade do governo em garantir a alimentação, entendendo a SAN de maneira fragmentada e descontextualizada.

Existe, entre os participantes do estudo, uma ideia predominante de que a nutrição fundamenta-se apenas em uma abordagem técnica, a qual envolve apenas o acompanhamento do crescimento e desenvolvimento das crianças e a maneira como as pessoas se alimentam. Dessa forma, acaba-se por reduzir os diversos aspectos que permeiam a SAN, prejudicando a reflexão-ação necessária para a efetividade da prática profissional.

De certa forma, o preenchimento do mapa de acompanhamento das famílias, quanto ao cumprimento da condicionalidade saúde, corrobora com a visão distorcida por parte dos trabalhadores. Ao analisar este documento percebe-se que a cobrança às unidades de saúde recai, fundamentalmente, sobre resultados técnico-estatísticos, como, por exemplo, dados de peso, estatura, situação vacinal das crianças e se esta se apresenta em aleitamento materno. Em relação às informações da mulher, segue-se a mesma lógica, focando apenas fatores como a data da última menstruação, se é gestante e se cumpriu o pré natal. Porém, é preconizado no Manual de Orientações sobre o Bolsa Família na Saúde, que, além da tomada dessas informações, ocorram atividades educativas em saúde, alimentação e nutrição ${ }^{24}$. 
SAN e o papel da saúde:

as ações são responsabilidade de quem?

Quando instigados a relacionar SAN com Saúde os profissionais pouco atentam para a inter-relação existente com o setor saúde. Demonstram apenas o entendimento sobre a interação das questões biológicas com a segurança alimentar e nutricional, como é demonstrado nas falas a seguir:

Eu acho que a saúde tá muito relacionada e tem que tá, porque é primordial. Antes de qualquer coisa tem que garantir uma alimentação saudável e segura às famílias para poder intervir nas outras coisas (E14).

Com certeza, né? Uma pessoa bem alimentada, ela, não vai ficar doente (E4).

Sim, pra ti ter saúde tu precisa ter uma boa alimentação (E21).

Mais da metade dos participantes do estudo relata que, na sua unidade, não ocorrem ações de SAN, ou, então, não sabem falar sobre o assunto, deixando de responder a indagação. Entre aqueles que fazem referência às ações de SAN, percebe-se pouca afinidade com o tema, pois as relacionam aos grupos e aos atendimentos. Estes últimos, quando questionados sobre que tipo de ações são essas, não conseguem descrevê-las.

Assim, evidencia-se que, os entrevistados, não conseguem visualizar os múltiplos fatores associados à Segurança Alimentar e Nutricional. Continuam atuando com base nos indicadores utilizados em 1990, quando as medidas antropométricas eram referência para avaliar a insegurança alimentar e nutricional das pessoas. Essa atitude deixa de lado as consequências psicossociais impostas por esta condição, bem como prejudica o entendimento da SAN como um direito ${ }^{25}$. Nesse sentido pode-se inferir que a falta de conhecimento dos profissionais em relação a esse processo acaba por engessar suas ações de promoção.

\section{PBF uma ferramenta para a promoção de SAN?}

Diante do exposto, busca-se compreender se os entrevistados reconhecem o programa como instrumento de promoção da SAN e do DHAA. Procura-se entender, também, se estes profissionais utilizam da condicionalidade atribuída, pelo $\mathrm{PBF}$, aos beneficiários, com vistas à promoção da qualidade de vida das pessoas e à ampliação do acesso ao serviço de saúde.

Na sequência de relatos, expostos a seguir, é possível identificar que não há concordância, entre os entrevistados, sobre a relação do programa com o DHAA e a SAN. Embora, em alguns casos, haja uma visão positiva do processo em questão, os profissionais atuam sem compreender corretamente as especificidades e os objetivos do programa:

Um dos objetivos do Bolsa Família, de certa forma, é instrumentalizar a família, para que, essa, possa ter um acesso a melhores condições de alimentação [...] (E1).

O objetivo do programa até seria melhorar a alimentação das famílias, mas, nem sempre, infelizmente, é o que acontece. Né? Eles usam para outros fins (E14).

Acho que ele não contribui nem assegura uma alimentação saudável. Ele é um programa que eu acho que tá meio perdido, assim. Tu vai lá e dá um valor em dinheiro pras pessoas, mas tu não garante que elas vão comer (E16).

Levando em consideração as falas expostas acima, considera-se importante investigar quais as informações que os sujeitos da pesquisa possuem sobre o programa. Esse processo certamente influenciará na maneira com que realizam o acompanhamento e a vigilância das famílias beneficiárias, fator, esse, de extrema relevância para a análise que se propõe com este estudo.

\section{Quais as informações que os profissionais dispõem sobre o programa?}

Certamente, as informações de direcionamento técnico, referentes à atividade profissional, são as mais facilmente assimiladas pelos profissionais em saúde. Existe, evidentemente, o conhecimento sobre como ocorre o cadastro de novas famílias. Os entrevistados relatam como se dá o processo. Ao descreverem a rotina de encaminhamento, referem-se à necessidade da família se dirigir ao setor de assistência social da região e contam, ainda, que o programa pressupõe um vínculo dos beneficiários com a unidade de saúde mais próxima de onde residem. Contudo, após falarem sobre o encaminhamento, não sabem explicar como ocorrem os demais tramites legais. Apenas esclarecem que, normalmente, fica a cargo dos profissionais de saúde fazerem a pesagem e o acompanhamento das famílias já cadastradas.

Com os relatos dos profissionais aparecem, também, dúvidas sobre vários aspectos, principalmente os que envolvem a distribuição do beneficio, a escolha de qual família vai receber e qual não vai, o tempo que esta família vai ficar recebendo o benefício e, até mesmo, a suposta aco- 
modação que estaria sendo gerada pelo programa. As falas a seguir demonstram essa falta de entendimento por parte dos sujeitos do estudo:

Oficialmente deveria ser pessoas com baixa renda, com uma renda per capita muito baixa. Mas, pelo o que agente vê, pelo o que agente constata, não é isso que acontece. Têm muitas pessoas que não comprovam o rendimento e que têm condições de viver sem o Bolsa (E5).

[...] como eu acho que essa bolsa não deveria ser para sempre, eu acho que deveria ser, assim, meio ano. Tu te organiza e vai trabalhar, porque tem muita gente que não trabalha e fica vivendo as custas de nós que trabalhamos (E6).

É importante ressaltar que, as dúvidas relatadas pelos participantes do estudo, são, em sua maioria, fruto das informações obtidas, sobretudo, através dos meios de comunicação de massa, a também chamada "grande mídia". São frequentes, nesses meios, as críticas que classificam a implantação das políticas sociais como assistencialistas e eleitoreiras. Além disso, segundo Castro et al. ${ }^{26}$, "no senso comum a principal restrição refere-se à transferência de recursos em si, que teria efeitos deletérios sobre a inserção no mercado de trabalho, de acomodação e de toda sorte de subterfúgios para manter o benefícios, até mesmo gerar mais filhos". Tais fatores estão diretamente relacionados com a maneira que os profissionais de saúde entendem o programa e, consequentemente, no reflexo desse processo na operacionalização da condicionalidade saúde.

\section{Acompanhamento e vigilância das famílias beneficiárias}

Em relação ao acompanhamento das famílias beneficiárias, nota-se que este ponto está claramente focado nas medidas de peso e altura e demais informações necessárias ao preenchimento do mapa. Dito de outra forma, o acompanhamento é feito principalmente com a intenção de completar o relatório que deve ser encaminhado à Secretaria Municipal de Saúde, processo que ocorre de seis em seis meses. Cada serviço organiza-se para realizar a mensuração das medidas antropométricas das pessoas. Alguns ainda conferem o calendário vacinal e as consultas realizadas, mas, poucos, orientam os usuários sobre o programa e, principalmente, como o beneficio deve ser utilizado. Certas equipes, diante da baixa procura dos beneficiários para o acompanhamento, tentam chamar a atenção das famílias atendidas com a formação de grupos, onde algo é oferecido em troca da participação, como, por exem- plo, remédio para vermes. As falas abaixo ilustram bem o que está sendo problematizado:

Peso, medidas, dados que são necessários pelo relatório que nos é enviado, só restrito a isso. Não é realizada nenhuma outra atividade, como um grupo, consultas programadas para essas pessoas que são cadastradas. Nada disso é realizado, é feito [...] (E1).

Quando a pessoa entra no $P B F$, ela recebe uma carteirinha que diz que, de seis em seis meses, ela tem que ter passado pelo posto de saúde. Então, ela, apresentando carteira de vacinas em dia, e que a criança foi pesada de seis em seis meses, e que ela compareceu ali, porque ela vai ter a assinatura do profissional. Esse é o controle (E2).

A gente diversifica um pouco, a gente faz um grupo com todos do Bolsa. Não faz só peso. A gente agora tá fazendo, tá passando remedinho de verme, piolho, orientação de higiene, aplicação de flúor, de higiene bucal, orientação nutricional (E16).

Nós fazemos um dia de peso. Se a família não pode esse dia, fica aberto. Nesse dia a gente pega as famílias de mais risco, que estão desempregado, têm mais tempo. Se trabalha, a gente pede para ir nas farmácias que tem balança, que sai tiquet, ou a gente dá atestado... Se não tiver a gente aqui, o técnico pode pesar (E23).

Quanto à vigilância das famílias, nota-se uma diversidade nas ações expostas pela fala dos profissionais. O que é compreendido quando se analisa os seguintes relatos:

Vigilância o quê? Das famílias quem faz... não existe... se existe, tanto da parte da saúde, quanto da assistência social, elas deveriam ter o acompanhamento mensal pra ver o que elas estão fazendo. O que elas estão evoluindo com esse valor que elas recebem (E2).

Não. Até é eles que cuidam para não perder o Bolsa Família, agora na época que tem o recadastramento. Eles vêm para não perder o vinculo, não perder a bolsa, e os que ficam sabendo vêm para levar os documentos, para receber a bolsa. Mas, fora disso, não tem mais acompanhamento (E3).

As informações envidas para a secretaria voltam para nós, dizendo o estado nutricional das pessoas, e, a gente, procura rever os casos que voltam. Se é o caso de marcar consulta, se marca consulta. Se é muito gritante a coisa a gente vai atrás sim. Geralmente a gente não espera o relatório, porque tu visualiza ali (E16).

No que tange a vigilância das famílias, a diversidade na prática dos profissionais, evidencia a dificuldade em serem plenamente atendidos os compromissos dos beneficiários do PBF. De acordo com o Manual de Orientações do Bolsa Famí- 
lia na Saúde, "o objetivo das condicionalidades do Programa é garantir a oferta das ações básicas (saúde, educação e assistência social), potencializando a melhoria da qualidade de vida das famílias e contribuindo para a sua inclusão social" ${ }^{24}$. Na prática, no entanto, o acompanhamento e a vigilância das famílias, estão voltados para medidas antropométricas, calendário vacinal e comparecimento as consultas ambulatoriais. Distanciando-se dos compromissos sociais propostos pelo programa e dos princípios que regem a SAN.

\section{Proposição para uma nova práxis do $\mathrm{PBF}$ : o âmbito socioafetivo do programa e a atuação profissional consciente}

Por fim, diante das questões apresentadas no transcorrer deste estudo, buscou-se, com o encaminhamento da entrevista, estimular os participantes a indicarem sugestões que, segundo eles, podem melhorar a operacionalização do PBF. As colaborações estiveram voltadas para quatro aspectos: 1) capacitação de todos os profissionais da equipe de saúde, com vistas a ampliar o entendimento dos objetivos e a essência do programa; 2) orientação para as famílias beneficiarias, capacitações para instrumentalização profissional e futura desvinculação do programa; 3 ) intersetorialidade efetiva, ou seja, que os três setores envolvidos no programa se articulem para melhorar o acompanhamento das famílias; 4) melhor fiscalização da parte do governo de turno, pois, por meio de suas vivencias, os participantes relatam conhecer muitas famílias que não necessitariam mais do auxilio, ou, pior, que nunca necessitaram. Ao mesmo tempo, sabe-se da existência de famílias que precisam desse beneficio e, muitas vezes, não conseguem recorrer a ele e acabam desamparadas.

Outro aspecto, não menos importante, está relacionado à necessidade de empatia dos profissionais de saúde para com as famílias beneficiárias, ressaltando a importância da solidariedade. Os trabalhadores que acompanham as famílias, principalmente os agentes comunitários de saúde (ACS), também descreveram a relação afetiva, estabelecida inevitavelmente com o acompanhamento, mais especificamente na pesagem dos indivíduos atendidos pelo programa.

Eu tô há 11 anos, então, eu vi. As crianças nasceram comigo e estão sendo acompanhados. Me chamam pela rua. Eu tenho uma ligação com eles como se fossem da minha família. Então, na hora de pesar, é como se fosse uma festa pra eles e, pra mim, é muito gratificante (E7).
É aquele momento que tu tá envolvido com a criança e com a mãe, mas é tão rápido. A gente sente que se puxa, às vezes ela não vem e a gente vai na creche, porque a gente sente que, se ela não vier pesar e medir, aquele dinheiro não vai vir para aquela criança e ela vai ter falta de alguma coisa (E22).

Olha, o sentimento quando tu vê uma família que entrou no Bolsa e, depois, tu vê a continuidade, principalmente se é nenezinho, e tu vê essa família se modificando pra melhor, ai tu tem um sentimento de dever cumprido. Mas quando tu vê uma família que entrou no Bolsa e continua a mesma coisa, tu te sente frustrado, então, no dia, tu tem dois sentimentos: de frustração e de dever cumprido (E23).

O fato de o ACS residir na comunidade onde trabalha, faz com que o profissional considere a realidade social dos beneficiários. Estando intimamente ligado à condição vivenciada no dia a dia das famílias atendidas pelo PBF, o profissional tende a ser mais sensível a esse processo. Conforme ressaltam Jardim e Lancman: "O ACS trabalha em uma microárea de sua comunidade. Enfatiza-se 'sua comunidade', pois além de trabalhar nela, o ACS é sujeito da mesma" ${ }^{27}$. Tal sentimento pode contribuir para a superação da mera instrumentalização do programa, desde que, este caráter solidário seja trabalhado na perspectiva das proposições apresentadas no Manual do Programa Bolsa Família na Saúde.

\section{Considerações finais}

Os pressupostos básicos do Sistema Único de Saúde (SUS), sobretudo a equidade das ações e a universalização do acesso ao serviço, além da recente inclusão da alimentação como direito social, ressaltam a complexidade do fenômeno aqui analisado e, obviamente indicam que esta discussão está longe de esgotar-se nestas linhas.

Nessa direção, dentre os aspectos abordados neste estudo, destaca-se a condicionalidade saú$\mathrm{de}$, pois se entende que, para avançar no processo operacional do PBF, ou seja, direcionar a prática dos profissionais para o contexto políticosocial que envolve o desenvolvimento do programa é preciso estar disposto a romper com a lógica instrumental que configura as relações sociais na sociedade capitalista. Processo esse, marcado pelo individualismo, a flexibilização do trabalho e a alienação da atividade profissional. Os trabalhadores precisam estar cientes que, além de promover o acesso ao serviço de saúde, é pre- 
ciso estar capacitado para ajudar a desenvolver mecanismos suficientemente capazes de redundarem na segurança alimentar e nutricional e no direito humano à alimentação adequada.

Procura-se, com isso, evidenciar a importância da formação e a constante capacitação dos profissionais que atuam nessa área, pois, ao desconectar a realidade social em que as famílias beneficiárias estão inseridas dos objetivos do programa, colabora-se para a simples mecanização dessas práticas. Nesse sentido, acredita-se que os profissionais de saúde precisam entender as proposições do programa como estratégias político-sociais, as quais, para além do alívio imediato, visam a gradativa superação dos problemas relacionados à pobreza, à fome e à miséria. Por isso, evoca-se o protagonismo consciente no exercício da prática profissional como alternativa ao cenário atual.
Considera-se que o processo de inclusão social depende do trabalho coletivo, multiprofissional e intersetorial. A promoção de ações isoladas não é suficiente para atingir os objetivos do programa. Cabe, também, a gestão municipal suplantar as dificuldades gerenciais, de modo a capacitar os trabalhadores de saúde com o intuito de superar a burocratização no acompanhamento das famílias beneficiárias. Não se pode exigir que o profissional de saúde assuma sozinho a responsabilidade pela concretização das diretrizes propostas pelo PBF. Para aproximar saúde e segurança alimentar e nutricional é preciso entender a urgência da interface entre essas áreas, o que resultará diretamente na melhora da qualidade de vida de milhares de brasileiros, em sua maioria, ainda excluídos pelo sistema político e econômico que rege as relações sociais no Brasil.

\section{Colaboradores}

CI Ramos desenvolveu o texto de todas as partes do artigo e MRM Cuervo orientou, revisou e auxiliou na elaboração do texto. 


\section{Referências}

1. Castro J. Geografia da Fome. São Paulo: Brasiliense; 1963.

2. Organização das Nações Unidas (ONU). Comitê dos Direitos Econômicos, Sociais e Culturais da ONU. Declaração Universal dos Direitos Humanos. Resolução 217 A (III). Assembléia Geral das Nações Unidas, 10 de dezembro de 1948. Genebra: ONU; 1948

3. Maluf RS. Segurança alimentar e nutricional. Petrópolis: Vozes; 2009.

4. Brasil. Emenda Constitucional $n^{\circ} 64$, de 4 de fevereiro de 2010. Altera o art. $6^{\circ}$ da Constituição Federal, para introduzir a alimentação como direito social. Diário Oficial da União 2010; 4 fev.

5. Brasil. Lei $\mathrm{n}^{\circ} 11.346$, de 15 de setembro de 2006 . Cria o Sistema Nacional de Segurança Alimentar e Nutricional. SISAN com vistas em assegurar o direito Humano à alimentação adequada e dá outras providências. Diário Oficial da União 2006; 16 set.

6. Brasil. Fome Zero. Brasília [2010]. [site na Internet]. [acessado 2011 jun 17]. Disponível em: http:// www.fomezero.gov.br/

7. Brasil. Ministério do Desenvolvimento Social e Combate a Fome. Bolsa Família. Brasília [2010]. [site na Internet]. [acessado 2011 jun 17]. Disponível em: http://www.mds.gov.br/bolsafamilia.

8. Burlandy MCMSL, Monnerat GL, Schottz V, Magalhães R. Programa bolsa família:nova institucionalidade no campo da política social brasileira? Rev. Katál. Florianópolis 2007; 10(1):86-94.

9. Burlandy MCMSL. Transferência condicionada de renda e segurança alimentar e nutricional. Cien Saúde Colet 2007; 12(6):1441-1451.

10. Minayo MCS, Sanches O. Quantitativo-qualitativo: oposição ou complementaridade? Cad de Saude Publica 1993; 9(3):239-262.

11. Minayo MCS. O desafio do conhecimento: pesquisa qualitativa em saúde. $8^{\text {a }}$ ed. São Paulo, Rio de Janeiro: Hucitec, Abrasco; 2004.

12. Flick U. Desenho de pesquisa qualitativa. Porto Alegre: Artemed; 2009

13. Fontanella BJB, Ricas J, Turato ER. Amostragem por saturação em pesquisas qualitativas em saúde: contribuições teóricas. Cad Saude Publica 2008; 24(1):17-27.

14. Brasil. Ministério do Planejamento, orçamento e gestão. Instituto Brasileiro de Geografia e Estatística. Censo demográfico. 2000. [site na Internet]. [acessado 2011 jun 12]. Disponível em: http://www.ibge. gov.br/home/estatistica/populacao/default_censo_ 2000.shtm.

15. Gil AC. Métodos e Técnicas de Pesquisa Social. 6a ed. São Paulo: Atlas; 2008.
16. Brasil. Ministério da Saúde (MS). Conselho Nacional de Saúde. Resolução 196/96. Diretrizes e normas regulamentadoras em pesquisa envolvendo seres humanos. Brasília: MS; 1996.

17. Bardin L. Análise de conteúdo. Trad. Luís Antero Reto e Augusto Pinheiro. Lisboa: Edições 70; 2002.

18. Valente F. A política de insegurança alimentar e nutricional no Brasil de 1995 a 2002, [2002]. [site na Internet]. [acessado em: 10 de junho de 2011]. Disponível em: http://www.fomezero.gov.br

19. Belik W, Silva JG, Takagi M. Políticas de combate à fome no Brasil. São Paulo Perspec. 2001; 15(4):119129.

20. Burity V, Franceschini T, Valente F, Recine E, Leão M, Carvalho MF. Direito humano à alimentação adequada no contexto da segurança alimentar e nutricional. Brasília: ABRANDH; 2010.

21. Pinheiro ARO. Análise histórica do processo de formulação da política nacional de segurança alimentar e nutricional (2003-2006): atores, idéias, interesses e instituições na construção de consenso político [tese]. Brasília: Universidade de Brasília; 2009.

22. Cotta RMM, Gomes AP, Maia TM, Magalhães KA, Marques ES, Siqueira-Batista R. Pobreza, Injustiça, e Desigualdade Social:repensando a formação de Profissionais de Saúde. Rev. Brasileira de Educação médica 2007; 31(2):278-286.

23. González AD, Almeida MJ. Integralidade da saúde - norteando mudanças na graduação dos novos profissionais. Cien Saude Colet 2010; 15(3):757-762.

24. Brasil. Ministério da Saúde (MS). Secretaria de Atenção à Saúde. Departamento de Atenção Básica. Manual de orientações sobre o Bolsa Família na Saúde. 2a ed. Brasília: MS; 2007.

25. Kepple AW, Segall-Corrêa AM. Conceituando e medindo segurança alimentar e nutricional. Cien Saude Colet 2011; 16(1):187-199.

26. Castro HCO, Walter MIMT, Santana CMB, Stephanou MC. Percepções sobre o Programa Bolsa Família na sociedade brasileira. Opinião pública 2009; 15(2):333-355.

27. Jardim TA, Lancmam S. Aspectos subjetivos do morar e trabalhar na mesma comunidade: a realidade vivenciada pelo agente comunitário de saúde. Interface Comun Saúde Educ 2009; 13(28):123-135.

Artigo aprovado em 20/10/2011

Apresentado em 01/11/2011

Versão final apresentada em 12/01/2012 